\title{
Apoptose no placentomo de cabras gestantes intoxicadas experimentalmente com cipó-preto - Tetrapterys multiglandulosa
}

\author{
[Apoptosis in the placentomo of pregnant goats experimentally intoxicated with \\ cipó-preto - Tetrapterys multiglandulosa] \\ P.P. Campos ${ }^{1}$, A.C. Vasconcelos ${ }^{1 *}$, M.M. Melo ${ }^{2}$ \\ ${ }^{1}$ Laboratório de Apoptose, Instituto de Ciências Biológicas da UFMG \\ Caixa Postal 2486 \\ 31270-010 - Belo Horizonte, MG \\ ${ }^{2}$ Escola de Veterinária da UFMG
}

\begin{abstract}
RESUMO
Estudou-se a ocorrência de apoptose nos placentomos de cabras gestantes intoxicadas experimentalmente com o cipó-preto (Tetrapterys multiglandulosa A.Juss.). Analisou-se morfometricamente a intensidade do processo de apoptose nas células trofoblásticas em cabras controle (grupo III) e em animais submetidos a diferentes dosagens (grupos I e II) de cipó-preto. O grupo I foi composto por quatro cabras gestantes que receberam 10gramas $/ \mathrm{kg}$ de peso vivo de folhas verdes da referida planta. No grupo II, quatro cabras gestantes receberam 20 gramas $/ \mathrm{kg}$ de peso vivo de folhas verdes. A quantificação morfométrica da apoptose demonstrou que nas cabras tratadas a apoptose ocorreu com maior intensidade quando comparada com a obtida em animais do grupo-controle. Diferentes dosagens da planta (10 e $20 \mathrm{~g} / \mathrm{kg} \mathrm{PV})$ não foram um fator determinante para a maior ou menor ocorrência de apoptose, apesar de acarretar morte fetal e subseqüente aborto em momentos diferentes. A intensa apoptose em fase ainda inicial da gestação compromete funções normais da placenta, possibilitando uma explicação para a morte fetal e aborto observadas. Conclui-se que a T. multiglandulosa é tóxica para cabras gestantes nas doses de $10 \mathrm{e}$ $20 \mathrm{~g} / \mathrm{kg}$ peso vivo ingeridas durante seis e duas semanas, respectivamente.
\end{abstract}

Palavras-chave: placenta, apoptose, cipó-preto, Tetrapterys multiglandulosa

\begin{abstract}
The role of apoptosis in the pathogenesis of placental dysfunction was studied in pregnant goats experimentally intoxicated with cipó-preto (Tetrapterys multiglandulosa A.Juss.). Twelve animals were distributed in three groups, each one with four pregnant goats. Group I was fed $10 \mathrm{~g} / \mathrm{kg}$ of live weight and group II was fed $20 \mathrm{~g} / \mathrm{kg}$ of live weight and group III was used as control. Although apoptosis occurred in placental cells of all the animals, morphometric analyses demonstrated that goats fed with cipó-preto showed higher apoptotic indices than controls. However no difference could be detected between groups I and II. Different amounts of the plant were not a determinant factor to increase the intensity of apoptosis in the placental tissue, although the final result was fetal death and/or abortion at different moments. Intense apoptosis during the early stage of pregnancy may be detrimental for the normal development and function of the placenta and may help to explain the fetal death and abortion observed. Therefore Tetrapterys multiglandulosa is toxic to pregnant goats when ingested at $10 \mathrm{or} 20 \mathrm{~g} / \mathrm{kg}$ of live weight during six or two weeks, respectively.
\end{abstract}

Keywords: placenta, apoptosis, cipó-preto, Tetrapterys multiglandulosa

Recebido para publicação em 27 de fevereiro de 2003

Recebido para publicação, após modificações, em 5 de setembro de 2003

*Autor para correspondência

E-mail: anilton@icb.ufmg.br 


\section{INTRODUÇÃO}

Entre as plantas da família Malpighiaceae descritas como tóxicas destaca-se a espécie Tetrapterys multiglandulosa A. JUSS. na região Sudeste do Brasil (Tokarnia et al., 2000). Vulgarmente conhecida como cipó-preto, cipóouro e cipó-ruão, trata-se de uma planta perene, trepadeira, com pétalas amarelas, folhas ovais a elíptico-lanceoladas. As folhas verdes constituem a parte tóxica, possuindo heterosídeos flavônicos, taninos condensados, alcalóides quaternários e esteróides (Melo et al., 2001).

As alterações mais conhecidas na intoxicação pelo Tetrapterys spp são de cunho degenerativonecrotizantes (Peixoto et al.,1995) e afetam principalmente órgãos como coração e fígado. $\mathrm{O}$ animal apresenta-se com edema na parte inferior da barbela e na região esternal. Pode ocorrer também dificuldade de locomoção, anorexia, tremores musculares e leve dispnéia nos bovinos. Nas regiões onde ocorre a doença em bovinos adultos há também abortos em vacas (Tokarnia et al., 1989).

Veterinários e criadores do vale do Rio Doce e Mucurí (MG) têm relatado problemas de abortos em vacas ou de neonatos fracos (com alta mortalidade perinatal), que ocorrem na época da seca, especialmente de agosto a outubro, quando os animais comem a brotação do cipó-preto que ainda se mantém verde. É provável que o cipópreto possua um princípio tóxico com efeito deletério sobre a gestação, interferindo na maturação e função placentária ou diretamente sobre $o$ feto causando morte fetal com subseqüente aborto (Melo et al., 2001).

O atraso na maturação placentária pode comprometer funções normais da placenta e acarretar sofrimento fetal e aborto. Um método de avaliação da maturação placentária consiste na quantificação da apoptose nas células trofoblásticas da placenta (Martins, 1999; Nunes et al., 2001).

Durante a gestação ocorrem mudanças estruturais na placenta, que estão relacionadas com sua subseqüente expulsão. $\mathrm{O}$ epitélio materno é colunar ou cuboidal, tornando-se achatado ao final da gestação, desaparecendo eventualmente em algumas áreas (Bjorkman, Sollen, 1960). O epitélio trofoblástico consiste, predominantemente, de células binucleadas (Lawn et al., 1996), que também diminuem ao longo da gestação (Williams et al., 1987).

A apoptose age como fator na maturação placentária sendo um mecanismo envolvido na diminuição do numero das células binucleadas (Martins, 1999; Nunes et al., 2001).

Se a apoptose ocorre de maneira mais intensa em fase ainda inicial da gestação, pode significar disfunção placentária (Kokawa et al., 1998). Assim, é importante a quantificação morfométrica da apoptose nas células trofoblásticas quando se suspeita de disfunção na maturação placentária.

A apoptose ou morte celular programada é um tipo de morte celular caracterizado por profundas modificações estruturais e funcionais (Wylle, 1992). Trata-se de um mecanismo fisiológico de controle da população celular que regula o tamanho dos tecidos, exercendo um papel oposto ao da mitose (Vasconcelos, 1995).

O objetivo deste trabalho foi de quantificar morfometricamente a apoptose nas células da placenta de cabras gestantes que receberam diferentes dosagens de cipó-preto e assim investigar o papel dessa alteração nas disfunções placentárias e no abortamento observado na intoxicação com o T. multiglandulosa.

\section{MATERIAL E MÉTODOS}

Foram utilizados 12 cabras (Capra hircus) prenhes da raça Saanen ou SRD, com idade variando entre dois e três anos e peso médio de $38 \mathrm{~kg}$. Os animais foram divididos em três grupos experimentais com quatro animais cada. $\mathrm{O}$ grupo I foi composto por cabras gestantes que receberam 10 gramas $/ \mathrm{kg}$ de peso vivo de folhas verdes de cipó-preto. No grupo II, as cabras gestantes receberam 20 gramas $/ \mathrm{kg}$ de peso vivo de folhas verdes. O grupo III foi o controle. Todo o acompanhamento clínico foi feito conforme descrito em Melo et al. (2001).

Após o abortamento, cada cabra tratada foi sacrificada e submetida à necropsia para colheita de fragmentos dos placentomos. Os animais do $\mathrm{G}$ III foram sacrificados e necropsiados em épocas de gestação equivalentes aos abortos ocorridos 
nos grupos I e II. A coleta das amostras e o processamento laboratorial foi feito conforme descrito em Melo et al. (2001).

As secções coradas em hematoxilina e eosina foram previamente examinadas ao microscópico óptico e posteriormente encaminhadas para a determinação do índice apoptótico em analisador de imagens ${ }^{1}$. As imagens obtidas dos campos histológicos em microscópio de luz foram digitalizadas com objetiva planacromática de 40 vezes.

O número mínimo representativo de campos microscópicos por placentomo para a determinação do índice apoptótico (IA) foi determinado a partir da contagem de células apoptóticas em 50 campos de um placentomo tomados aleatoriamente. Desses, formaram-se 10 subamostras de 5, 10, $15 \ldots$ até 50 campos retirados aleatoriamente com reposição. De cada grupo calcularam-se a média aritmética e os respectivos erros-padrão para cada tamanho da amostra. Plotou-se em gráfico a evolução dos erros-padrão obtidos para cada tamanho amostral. À medida que o tamanho da amostra aumentou, os erros diminuíram. Assim, o tamanho da amostra considerado como mínimo representativo foi obtido quando o incremento do número de campos não resultou em redução considerável no valor do erro (Sampaio, 1998).

Das 12 amostras contaram-se todas as células com morfologia sugestiva de apoptose e posteriormente todas as demais células presentes no número mínimo representativo de campos histológicos pertencentes a interface maternofetal de cada lâmina. Em cada campo o IA utilizado referiu-se a porcentagem de células apoptóticas por campo microscópico e foi obtido conforme a seguinte equação:

$\mathrm{IA}=\left(\frac{\sum \text { de células em apoptose }}{\sum \text { de células totais }}\right) \times 100$.

De todos os campos estudados para cada amostra calculou-se a média aritmética do IA resultando em um valor médio por amostra.

Para a quantificação de células apoptóticas, foram contadas somente as células que apresentaram pelo menos três das seguintes

${ }^{1}$ Kontron Elektronic GMBH - KS300 versão 2.0. características morfológicas peculiares do processo: anoiquia, condensação do citoplasma, condensação nuclear, fragmentação nuclear, fragmentação celular e fagocitose dos corpos apoptóticos pelas células da vizinhança na ausência de inflamação exsudativa.

Os corpos apoptóticos em grande número e próximos uns dos outros foram quantificados como o resultado de uma única célula em apoptose. Quando distantes entre si, foram considerados como resultados de apoptose em células diferentes e contabilizados como tal.

Na dúvida quanto a caracterização de uma célula como em apoptose, ela não foi contabilizada como tal.

As médias de cada tratamento foram comparadas entre si pelo do teste $t$ de Student, para duas amostras em par para médias com nível de significância de 5\%, utilizando-se do programa Microsoft ${ }^{\circledR}$ Excel 2000 (versão 9.0).

\section{RESULTADOS E DISCUSSÃO}

A apoptose pôde ser facilmente detectada pelas características morfológicas descritas nos critérios de inclusão empregados neste trabalho. As células retraídas e destacadas de suas vizinhas, com cromatina condensada, com núcleo retraído e ou fragmentado, foram facilmente reconhecidas como apoptóticas, mesmo à coloração de rotina (Fig. $1 \mathrm{a}$ e b).

Na necrose, a condensação da cromatina dá se de forma grosseira seguida de ruptura nuclear. Ao contrário, na apoptose a condensação da cromatina dá-se de forma organizada, freqüentemente periférica à carioteca, às vezes com formação de "crescentes", seguida de fragmentação sem ruptura nuclear, como já mencionado por Staunton e Gaffney (1998).

Diversas colorações e técnicas especiais (ex: verde de metila - pironina - MGP, Shorr, Túnel) têm sido propostas e utilizadas na marcação de células apoptóticas. Moffitt (1994) utilizou o MGP e a HE para demonstrar morte celular em tumor murino S180. O verde de metila enfatiza as células apoptóticas devido à evidenciação da cromatina condensada e a pironina cora bem o citoplasma das células apoptóticas devido ao 
aumento de RNAm, diferentemente do que ocorre nas células necróticas. Entretanto, ao se comparar os resultados da quantificação do índice apoptótico das sessões coradas por MGP e por HE, nenhuma diferença estatística foi observada.

Também Nunes (2001) observou que não houve diferenças significativas entre os IA obtidos em diversas colorações como Shorr e MGP. Gonzalez et al. (2000) utilizaram apenas a coloração pela HE para quantificar as células em apoptose, no estudo de regressão do TVTC induzido terapeuticamente.

Assim, independente da técnica utilizada, o mais importante na detecção da apoptose é ter um critério de inclusão bem definido e coerente. Kerr et al. (1972) salientaram que a presença da morfologia padrão de apoptose envolvendo a condensação da cromatina e a fragmentação citoplasmática em corpos apoptóticos, como visto na Fig. 1 a e b, é suficiente para identificação histológica da apoptose.

A morfometria (Fig. 2) dos índices apoptóticos obtidos nos 30 campos dos 12 animais divididos nos três tratamentos demonstrou não haver diferenças significativas na freqüência de apoptose nas células placentárias entre os grupos I e II, quando examinadas após abortamento dos fetos (Tab. 1). A frequência relativa de apoptose encontrada do III (controle) foi significativamente inferior à dos grupos I e II, indicando que a planta possui propriedades próapoptóticas, independente da quantidade da planta ingerida.

Tabela 1. Média e erro-padrão do índice apoptótico (IA \%) nos placentomos de cabras dos grupos tratados com $10 \mathrm{~g} / \mathrm{kg} \mathrm{PV}$, com $20 \mathrm{~g} / \mathrm{kg}$ PV e controle

\begin{tabular}{ccc}
\hline Grupo & Média IA & Erro-padrão \\
\hline I $(10 \mathrm{~g} / \mathrm{kg})$ & 44,1 & 2,0 \\
II $(20 \mathrm{~g} / \mathrm{kg})$ & 43,0 & 1,6 \\
III (Controle) & 20,6 & 0,9 \\
\hline
\end{tabular}

A apoptose observada nos animais do grupocontrole foi considerada fisiológica, como parte da maturação placentária. Durante a gestação, o epitélio placentário se modifica, adaptando-se às demandas fisiológicas. No terço final da gestação começa a ocorrer um processo de involução, preparatório para o parto (Grunert et al., 1976; Grunert, 1980; Barreto Filho, Marques Júnior, 1993). A apoptose participa ativamente nesse processo de maturação placentária, como demonstrado por Martins (1999), Marques Júnior et al. (2001) e Nunes et al. (2001).

A maior incidência de apoptose em fase ainda inicial da gestação observada nas placentas dos animais dos grupos I e II compromete funções normais da placenta e participa de alguma maneira na morte do feto e posterior abortamento. Kokawa et al. (1998) salientaram que a apoptose intensa em fase ainda inicial da gestação associa-se com disfunção placentária.

No grupo I, abortamentos ocorreram após a quinta semana de ingestão da planta e no grupo II após a segunda semana. Assim, ainda que não tenham sido observadas diferenças microscópicas e morfométricas no tocante à apoptose placentária, clinicamente a ingestão de maior quantidade da planta induziu morte fetal e abortamentos mais precoces, encurtando o período experimental no grupo II. Especula-se que se a morte fetal e o abortamento não tivessem ocorrido tão cedo no grupo II, de maneira que se pudesse continuar o tratamento com 20 gramas $/ \mathrm{kg}$ PV até cinco semanas, o índice de apoptose provavelmente seria maior do que o do grupo I. Assim, dosagens maiores da planta acabaram levando a um período de exposição menor, com abortamentos mais precoces.

Os resultados obtidos neste estudo parecem sustentar que a ingestão de cipó-preto aumenta a apoptose celular numa fase ainda inicial da gestação, comprometendo a saúde fetal e ajudando a explicar a ocorrência de morte fetal e abortamento. 

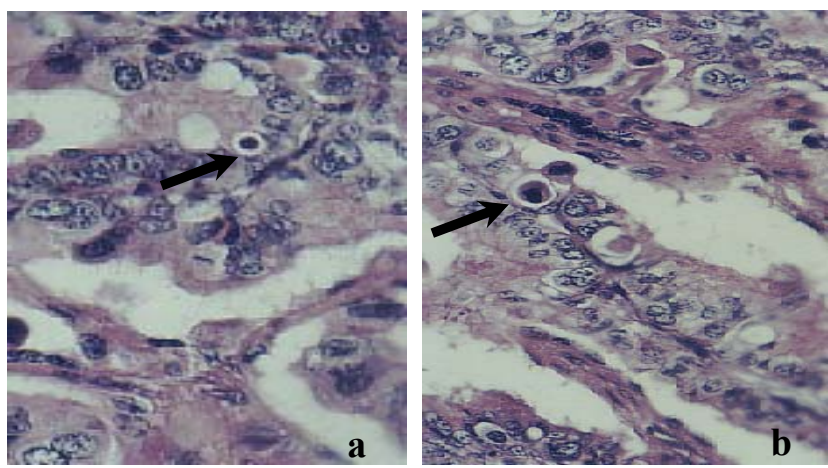

Figura 1 a e b. Placenta de caprino do grupo II (20g/kg PV de cipó-preto) apresentando células com morfologia características de apoptose (HE, 132x).

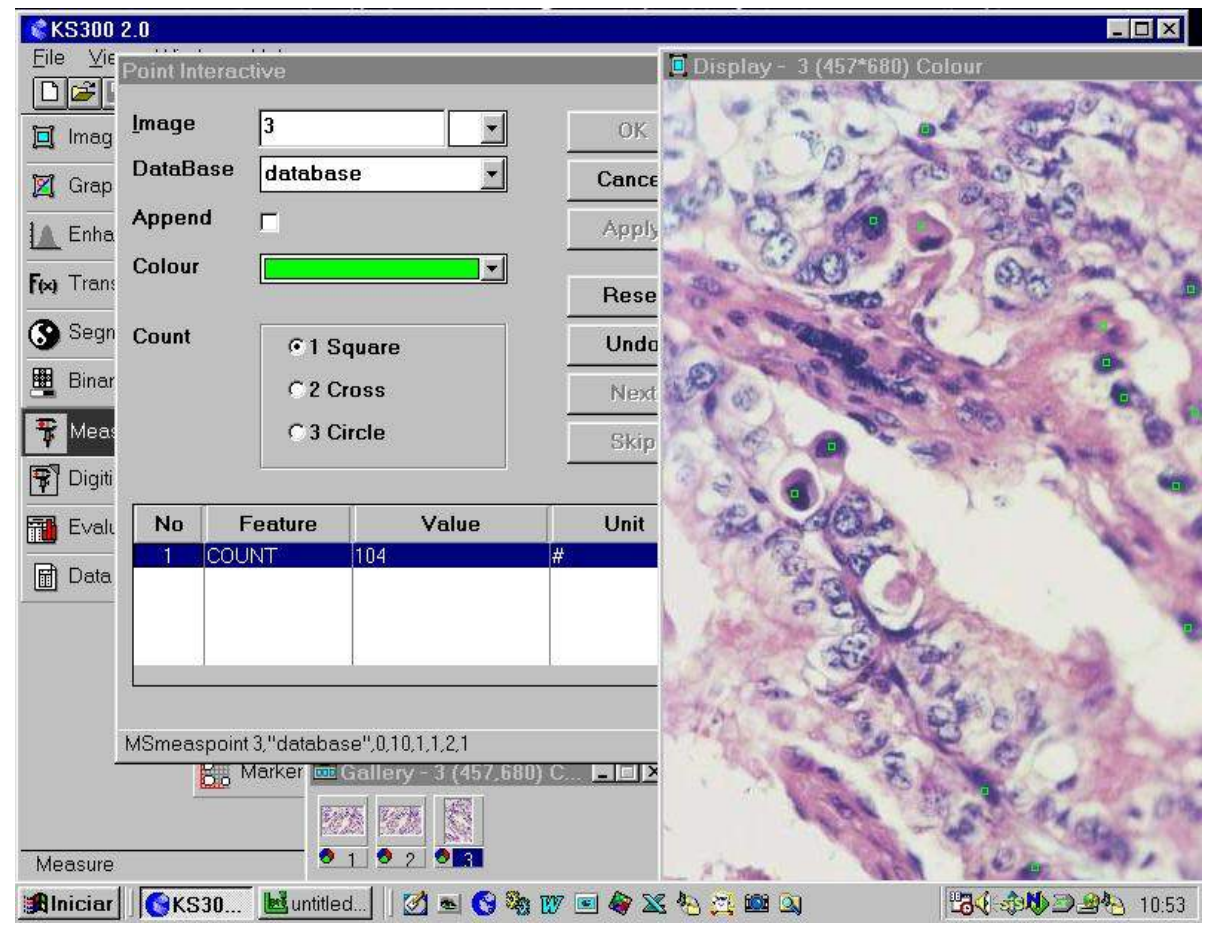

Figura 2. Tela do analisador de imagens utilizado para a quantificação das células apoptóticas e totais de cada campo histológico.

\section{CONCLUSÕES}

A intensa apoptose na fase ainda inicial da gestação compromete as funções normais da placenta, explicando a morte fetal e o aborto observadas na intoxicação experimental com $T$. multiglandulosa em cabras gestantes.

\section{REFERÊNCIAS BIBLIOGRÁFICAS}

BARRETO FILHO, J.B.; MARQUES JUNIOR, A.P. Aspectos histológicos da placenta de vacas zebu. Arq. Bras. Med. Vet. Zootec., v.45, p.385393, 1993. 
BJORKMAN, N.; SOLLEN, P.A. Morphology of bovine placenta at normal delivery. Acta Vet. Scand., v.1, p.347-362, 1960.

GONZALEZ, C.M.; GRIFFEY, S.M.; NAYDAN, D.K. et al. Canine transmissible venereal tumour: a morphological and immunohistochemical study of 11 tumours in growth phase and during regression after chemotherapy. J. Comp. Pathol., v.122, p.241248, 2000.

GRUNERT, E. Etiology of retained bovine placenta. In: MORROW, D. A. Current therapy in theriogenology. Philadelphia: W. B. Saunders, 1980, p.180-186.

GRUNERT, E.; SCHULZ, C.; AHLERS, D. Retained placenta problems with induced labor in cattle. Ann. Rech. Vét., v.7, p.135-138, 1976.

KERR, J.F.R.; WYLLIE, A.H.; CURRIE, A.R. Apoptosis: basic biological phenomenon with wideranging implications in tissue kinetics. $B r . J$. Cancer, v.26, p.239-257.1972.

KOKAWA, K.; SHIKONE, T.; NAKANO, R. Apoptosis in human chorionic villi and deciduas during normal embryonic development and spontaneous abortion in the first trimester. Placenta, v.19, p.21-26, 1998.

LAWN, A.M.; CHIQUOINE, A.D.; AMOROSO, E.C. The development of the placenta in the sheep and goat: an electron microscope study. Vet. Res., v.27, p.343-346, 1996.

MARQUES JUNIOR, A.P.; MARTINS, E.; VASCONCELOS, A.C. et al. Apoptosis in placenta maturation and expulsion in Bos taurus taurus. In: CONFERENCE OF THE EUROPEAN PLACENTA GROUP, 9., 2001, Sorrento, Itália. Anals... Sorrento, 2001, p.32.

MARTINS, V.M.V. Maturação e expulsão placentária em Bos taurus taurus e Bos taurus indicus. 1999. 110f. Tese (Doutorado). Escola de Veterinária, Universidade Federal de Minas Gerais, Belo Horizonte.

MELO, M.M.; VASCONCELOS, A.C.; DANTAS, G.C. et al. Experimental intoxication of pregnant goats with Tetrapterys multiglandulosa A. Juss. (Malpighiaceae). Arq. Bras. Med. Vet. Zootec., v.53, p.58-65, 2001.

MOFFITT, P.A methyl green-pyronin technique for demonstrating cell death in the murine tumour S180. Cell Biol. Int., v.18, p.677-679, 1994.

NUNES, J.E.S. Maturação e eliminação placentária de bovinos: determinação do índice apoptótico e reação de tunel. 2001. 69f. Dissertação (Mestrado) - Escola de Veterinária, Universidade Federal de Minas Gerais, Belo Horizonte.

NUNES, J.E.S.; VASCONCELOS, A.C.; MARTINS, E. et al. Maturação e liberação placentária em bovinos e sua relação com apoptose. Rev. Bras. Reprod. Anim., v.25, p.513-525, 2001

PEIXOTO, P.V.; LORETTI, A.P.; TOKARNIA, C. H. "Doença do peito inchado", Tetrapterys spp poisoning, brisket disease and St. George disease: a comparative study. Pesq. Vet. Bras., v.15, p.43-50, 1995.

SAMPAIO, I.B.M. Estatística aplicada à experimentação animal. Belo Horizonte: Fundação de Ensino e Pesquisa em Medicina Veterinária e Zootecnia, 1998. 221p.

STAUNTON, M.J.; GAFFNEY, E.F. Apoptosis. Basic concepts and potential significance in human cancer. Arch. Pathol. Lab. Med., v. 122, p.310-319, 1998.

TOKARNIA, C.H.; DOBEREINER, J.; PEIXOTO, P.V. Plantas tóxicas do Brasil. Helianthus. Rio de Janeiro, 2000. 310p.

TOKARNIA, C.H.; PEIXOTO, P.V.; DOBEREINER, J. et al. Tetrapterys spp (Malpighiaceae), a causa de mortandades em bovinos caracterizadas por alterações cardíacas Pesq. Vet. Bras., v.9, p.23-44, 1989.

VASCONCELOS, A.C. Apoptose ou morte celular programada e sua importância em patologia veterinária. In: ENCONTRO NACIONAL DE PATOLOGIA VETERINÁRIA, 7., 1995, Belo Horizonte. Anais... Belo Horizonte, 1995. p.69.

WILLIAMS, W.F.; MARGOLIS, M.J.; MANSPEAKER, J. et al. Peripartum changes in the bovine placenta related to fetal membrane retention. Theriogenology, v.28, p.211-223, 1987.

WYLLIE, A.H. Apoptosis and the regulation of cell numbers in normal and neoplastic tissues: an overview. Cancer Metast. Rev., v.11, p.95-103, 1992. 